\title{
Desafios da Área de Recursos Humanos - Visão dos Dirigentes das EMPREsas e doS Profissionais da Área de RH
}

Lúcia Maria Barbosa de Oliveira*

\section{Introdução}

área de recursos humanos hoje está sendo assunto de grandes dis-
cussões, já não se podendo pensar mais em melhoria de qualidade,
aumento de produtividade sem envolver aspectos como treinamento, retreinamento, remuneração variável, competência essencial da empresa entre outros. Todos estes aspectos estão ligados à área de RH.

Nos países desenvolvidos se discute a participação da área na formulação dos planos estratégicos (ver por exemplo, Livy, 1988; Armstrong, 1987; Georgiade, 1990; Guest \& Hoque, 1994; e Truss, 1996 ). Outros autores discutem a maneira de formular as estratégias da área, orientadas para o atingimento dos objetivos organizacionais (ver por exemplo, Cook \& Armstrong, 1990; Connock, 1992; Boxall, 1994; Tyson \& Witcher, 1994; Armstrong, 1994; e Ulrich, 1998).

Além disso já é destacado que a responsabilidade por RH não é somente do "Departamento de Recursos Humanos" e sim como diz Ulrich (1998, p.282) " envolve uma comunidade de recursos humanos mais ampla em uma empresa. A comunidade de RH consiste daqueles indivíduos de toda a organização que se dedicam a acionar práticas de $\mathrm{RH}$ para arquitetar e integrar capacidades organizacionais que possam criar valor e produzir resultados".

" PhD em Relações Industriais pela London School of Economics and Political Science; Mestre em Administração pela UFMG;

Professora Adjunta do Departamento de Ciências Administrativas da Universidade Federal de Pernambuco;

Coordenadora do Curso MBA-Executivo em Gestão de Pessoas da UFPE;

Pesquisadora do CNPq. 
Truss (1996, p.36) destaca que o resultado de uma pesquisa realizada na London Business School entre os CEOs - Chief Executives Offices das 1000 maiores empresas listadas na Times indica que no ano 2010 a função de recursos humanos estará mais estratégica e alinhada à administração das pessoas e aos objetivos globais do negócio. Além disso, indica que mais de dois terços dos respondentes concordaram que as empresas precisarão cada vez mais de pessoas com habilidades gerais em um grande arranjo de atividades. Assim acrescenta (ibid, p, 37) "isto confirma que a função de recursos humanos terá um papel estratégico aumentado para desempenhar na análise e entendimento da futura direção do negócio e na colocação no lugar apropriado de programas de recrutamento, treinamento e desenvolvimento".

O resultado de outra pesquisa conduzida pela empresa de Consultoria Americana Tower Perrin em 1991, com o apoio financeiro da IBM, abrangendo 2991 executivos de diversos países, mostra as prioridades de recursos humanos para obter vantagem competitiva no Século XXI. A pesquisa indica que $\mathrm{RH}$ deverá desempenhar um novo papel:

- capaz de responder a um mercado altamente competitivo e à estrutura de negócios globais;

- intimamente ligado aos planos estratégicos do negócio;

- conjuntamente concebido e implementado pelos executivos de linha e de recursos humanos;

- capaz de focalizar sua atenção na qualidade, serviço ao consumidor, produtividade;

- envolvimento do empregado, equipes de trabalho e flexibilidade da força de trabalho.

Segundo Schuler \& Huber (1993, p.5): "o aumento da atenção dada a como as empresas administram os recursos humanos é atribuído ao reconhecimento que uma efetiva administração dos recursos humanos tem um impacto positivo na direção global da empresa e, definitivamente no bottom line. $O$ termo bottom line refere-se a sobrevivência, crescimento, lucratividade, competitividade e flexibilidade em adaptar-se às mudanças de condições ". 
Desafios da Área de Recursos Humanos - Visāo dos Dirigentes das Empresas e dos Profissionais da Área de RH

Desta forma, a condução da administração de recursos humanos de forma eficaz tem um positivo efeito no atingimento dos resultados finais da organização. Em particular, os países desenvolvidos estão enfatizando bastante esta área. Mas, no Brasil, o que está ocorrendo?

Resende $(1994$, p.9) afirma que nos últimos 40 anos de existência da área de RH no Brasil verificaram-se poucos avanços em diversos planos e subsistemas. Segundo ele, isto ocorreu devido às seguintes razões: a) miopia empresarial, com os dirigentes alocando parcos recursos à área; b) a crise dos últimos anos que provocou mais retrocesso do que evolução da área de $\mathrm{RH} ; \mathrm{c}$ ) acomodação dos profissionais de $\mathrm{RH}$ das empresas, sendo mais apegados ao tecnicismo do que a apresentar contribuições efetivas aos resultados prioritários e negócios da empresa. Entretanto, o autor mostra a necessidade de introdução de novos paradigmas de RH para a sobrevivência e êxito das empresas brasileiras.

Curado et alii (1995, p.7) em pesquisa recente realizada em mais de 200 empresas do Estado de São Paulo mostram como resultados que a gestão, as práticas e as políticas de $\mathrm{RH}$ apresentam um cenário pouco avançado. E acrescentam que se forem levadas em considerações as discussões em torno da importância de valorização do elemento humano e a transformação necessária à área de $\mathrm{RH}$ para que a empresa obtenha maior competitividade no Brasil, é de se esperar profundas mudanças na sua gestão, já que as empresas estão passando por um momento de transição.

Ainda nessa linha, levando em consideração os novos modelos de administração emergentes, exigindo novos perfis dos empregados para trabalharem em sistemas onde predominam trabalhos em equipes e aprendizagem constante, há de se esperar novas formas de atuação da área de RH. Neste sentido, Gonçalves (1997, p.18) destaca: "à medida que as pessoas mudam, todos os sistemas da área de RH deverão ser repensados a partir do zero". Desta forma, necessário se faz o desenvolvimento de sistemas, por exemplo, de avaliação do desempenho, de remuneração e de seleção, de forma a atender à essa nova realidade.

Assim, os dirigentes das empresas tenderam a relegar a segundo plano a área de RH no País. E agora, com este novo cenário de maior competitividade e movimento de qualidade total, que desafios são enfrentados pelos profissionais de RH para que obtenham eficácia em seu desempenho? 
Este trabalho, que foi baseado em duas pesquisas desenvolvidas, procura mostrar os desafios enfrentados pelos executivos de $\mathrm{RH}$ na sua própria visão e sob a ótica dos dirigentes das empresas. Será que eles têm os mesmos pontos-de-vista? Conhecendo-se como os dirigentes pensam sobre a área e como os profissionais se vêem atuando, é possível se traçar um cenário de convergência ou divergência que irá atuar como facilitador ou mesmo dificultador da área de RH.

\section{Metodologia}

O trabalho engloba resultados de duas pesquisas distintas realizadas em períodos diferentes: a primeira tem como população as 586 maiores empresas do Brasil classificadas na Exame "Melhores e Maiores" edição agosto, 1993, incluindo empresas privadas e públicas. Sendo os dados coletados dos responsáveis pela área de recursos humanos. A segunda tem como população as 489 maiores empresas do Brasil classificadas na Exame "Melhores e Maiores"- edição agosto, 1995 e os dados foram obtidos de seus executivos da alta direção.

O mesmo questionário foi aplicado nos dois estudos. Além disso, os dados foram coletados através de questionários enviados pelo correio nas duas pesquisas. Este método é confiável e de baixo custo e tem sido muito usado em estudos em nível nacional e internacional, onde os respondentes estão geograficamente dispersos. Oliveira \& Moraes (1994, p.86-88) indicam regras básicas para utilização do método de forma a trazer bons resultados.

Como resultado, foram obtidas 299 respostas dos responsáveis pela área de $\mathrm{RH}$ e 95 dos dirigentes das empresas, o que corresponde, respectivamente, a $51,0 \%$ e $19,4 \%$ da população de cada pesquisa. Tais números foram considerados significativos e representativos de cada população estudada.

\section{Caracterização dos Responsáveis pela área de RH e dos dirigentes das empresas}

Aqueles que são responsáveis pela unidade organizacional de $\mathrm{RH}$ apresentam o seguinte perfil demostrado no Quadro 1, na página seguinte. 
Desafios da Área de Recursos Humanos - Visão dos Dirigentes das Empresas e dos Profissionais da Área de RH

Quadro 1- Perfil dos responsáveis pela área de RH

\begin{tabular}{|lc|}
\hline Características & $\%$ \\
\hline Sexo masculino & 79,5 \\
\hline Idade superior a 35 anos & 78,1 \\
\hline Formação superior em administração & 43,5 \\
\hline Formação superior em psicologia & 17,6 \\
\hline Não realizaram curso de pós-graduação & 52,9 \\
\hline Não realizaram especialização em RH & 70,2 \\
\hline Experiência prévia de mais de seis anos antes de entrar no atual emprego & 50,3 \\
\hline
\end{tabular}

O cargo ocupado está, em sua maioria, no nível de gerência $(63,5 \%)$ correspondendo ao segundo nível da estrutura organizacional. Esta situação é favorável ao executivo, visto que ele pode ter mais chance de opinar e participar do planejamento global e estratégico da empresa, fato clamado por diversos autores (ver por exemplo, Georgiades, 1990; Guest \& Hoque, 1994; e Ulrich, 1998).

Os dirigentes das empresas apresentam as características demonstradas no Quadro 2. Como pode ser visto, houve uma preocupação de alguns dirigentes de se especializarem em administração, fato que denota que é uma área que tem um campo aberto para desenvolvimento de cursos desta natureza voltados para executivos de alto nível.

O cargo ocupado pelos dirigentes é em nível de primeiro escalão $(88,0 \%)$, ou seja, de presidência, superintendência ou diretoria. Portanto, são pessoas que estão diretamente ligadas aos estabelecimentos de planejamentos globais e estratégicos das empresas, cujas decisões influem no destino das organizaçōes.

\section{Quadro 2 - Perfil dos dirigentes das empresas}

\begin{tabular}{|lc|}
\hline Características & $\%$ \\
\hline Sexo masculino & 96,8 \\
\hline Idade superior a 45 anos & 60,0 \\
\hline Formação superior em engenharia & 46,5 \\
\hline Formação superior em administração & 15,1 \\
\hline Não realizaram curso de pós-graduação & 53,1 \\
\hline Dos 46,9\% que realizaram pós-graduação, fizeram especialização & 65,8 \\
\hline Especialização em Administração & 56,6 \\
\hline Mestrado & 26,3 \\
\hline Doutorado & 5,3 \\
Experiência prévia antes de entrar no atual emprego acima de 10 anos & 67,4 \\
\hline
\end{tabular}




\section{Desafios enfrentados pelos executivos de RH - Visão dos dirigentes e a ótica dos profissionais da área}

A Tabela 1 indica os principais desafios enfrentados pela área de recursos humanos. Os dirigentes apontaram o seu grau de concordância segundo a escala de quatro pontos: CT (1) ; concordo totalmente; $\mathrm{C}(2)$ concordo; D(3) discordo e DT(4) discordo totalmente.

Desta forma, quanto mais perto de 1 a média ponderada encontrada, maior é a concordância dos executivos com os desafios descritos.

Verifica-se que os dirigentes apontaram como sendo os cinco mais importantes desafios, ou sejam, os itens que obtiveram melhores médias, isto é, aquelas mais próxima de 1, os seguintes:

- atuar como agente de mudança;

- manter com o sindicato laboral uma relação madura capaz de gerar uma satisfação mútua;

- manter-se tecnicamente atualizado com assuntos ligados a RH;

- demonstrar às demais áreas a importância de RH como função de apoio às mesmas;

- utilizar a informática como ferramenta facilitadora / agilizadora dos trabalhos.

Como pode ser verificado, os dirigentes indicaram como principal desafio para a área de $\mathrm{RH}$, a sua atuação como agente de mudança, e isto vem ao encontro de Resende (1994, p.10) que indica a necessidade de mudanças de paradigmas em RH para a obtenção de êxito, desde a sua forma de atuação, a estruturação da área e a apresentação de novas formas de conduzir os diversos subsistemas de $\mathrm{RH}$, tendo em vista a competitividade, avanços tecnológicos, programas de qualidade e melhoria da produtividade.

O executivo de $\mathrm{RH}$ precisa atuar como agente de mudança, segundo Prahalad (1997, p.8): "o conceito de competência essencial está revolucionando as teorias da competitividade. A organização dos recursos humanos deve ter como eixo essa vantagem, que também requer certa dose de "desaprendizado" pelas empresas". Desta forma, a atuação do executivo de RH necessita mudar e existe todo um espaço aberto para que ele possa desem- 
Desafios da Área de Recursos Humanos - Visäo dos Dirigentes das Empresas e dos Profissionais da Área de RH

penhar esse papel de agente de mudança, saindo na vanguarda para introduzir esses novos paradigmas como, por exemplo, o de competência essencial (core competence) que é o conceito de habilidade cumulativa básica na organização.

\section{Tabela 1 - Desafios enfrentados pela área de recursos Humanos - Ótica dos dirigentes}

\begin{tabular}{|c|c|c|c|c|c|c|c|}
\hline \multirow[t]{2}{*}{ Desafios } & \multirow{2}{*}{$\begin{array}{c}\mathrm{N}^{\circ} \\
\text { de casos }\end{array}$} & \multirow{2}{*}{$\begin{array}{l}\text { média } \\
\text { geral }\end{array}$} & \multirow{2}{*}{$\begin{array}{l}\text { desvio } \\
\text { padrão }\end{array}$} & \multicolumn{4}{|c|}{ Grau de concordância (\%) } \\
\hline & & & & CT (1) & $\mathrm{C}(2)$ & $\mathrm{D}(3)$ & DT (4) \\
\hline D6 & 92 & 1,52 & 0,60 & 52,2 & 44,6 & 2,2 & 1,1 \\
\hline D1 & 92 & 1,62 & 0.73 & 50,0 & 41,3 & 5,4 & 3,3 \\
\hline D10 & 93 & 1,68 & 0,76 & 47,3 & 40,9 & 8,6 & 3,2 \\
\hline D3 & 93 & 1,75 & 0,73 & 38,7 & 50,5 & 7,5 & 3,2 \\
\hline$\overline{\mathrm{D} 7}$ & $\overline{93}$ & 1,75 & 0,71 & 38,7 & 49,5 & 9,7 & 2,2 \\
\hline D9 & 93 & 1,75 & 0,76 & 40,9 & 46,2 & 9,7 & 3,2 \\
\hline $\mathrm{D} 2$ & 93 & 1,78 & 0,81 & 41,9 & 41,9 & 11,8 & 4,3 \\
\hline D4 & 93 & 1,82 & 0,72 & 33,3 & 54,8 & 8,6 & 3,2 \\
\hline D5 & 93 & 1,97 & 0,89 & 32,3 & 47,3 & 11,8 & 8,6 \\
\hline $\mathrm{D} 8$ & 93 & 2,25 & 0,81 & 17,2 & 47,3 & 29,0 & 6,5 \\
\hline
\end{tabular}

$\mathrm{D} 1$ = manter com o sindicato laboral uma relação madura capaz de gerar satis fação mútua.

D2 = demonstrar à direção a importância da função de RH para atingimento dos objetivos da empresa.

D3 = demonstrar às demais áreas a importância de RH como função de apoio às mesmas.

D4 = criar meios que demonstrem a eficácia da área de RH.

D5 = obter apoio da direção para planos, programas e ações.

D6 = atuar como agente de mudança.

D7 = utilizar a informática como ferramenta facilitadora/agilizadora dos trabalhos.

D8 = conseguir poder, credibilidade e autonomia para a área de RH.

D9 = planejar as atividades de RH.

$\mathrm{D} 10=$ manter-se tecnicamente atualizado com assuntos ligados a RH.

$\mathrm{CT}=$ concordo totalmente

$\mathrm{C}=$ concordo

$\mathrm{DT}=$ discordo totalmente

$\mathrm{D}=$ discordo 
Outro item bastante indicado pelos dirigentes foi manter com o sindicato laboral uma relação madura e capaz de gerar satisfação mútua. Realmente, tal aspecto é de suma importância. Os empregados são atraídos para os sindicatos por que estão insatisfeitos com aspectos, tais como: condiçōes de trabalho, sistemas de remuneração e comunicações inadequadas com as supervisões. Historicamente, sindicatos e a administração das empresas têm atuado em direções opostas. Mas torna-se necessário, cada vez mais, o estabelecimento de boas relações. Neste sentido, Schuler $\&$ Huber (1993, p.732) advertem: "finalmente, como as condições econômicas no mundo têm mudado substancialmente, também tem ocorrido nas relações de administração-sindicato. Há mais cooperação. A administração vê as relaçōes cooperativas como um instrumento na implementação de estratégias de melhoria de qualidade. Os sindicatos vêem as relações cooperativas como instrumentos para proteger os cargos e rendimentos de seus membros. E a sociedade como um todo vê a relação de cooperação como necessária e apropriada nesta época de intensa competição global."

Mas no Brasil somente na década de 70 com o início da abertura política e a revitalização do movimento sindical e a maior preocupação com os temas participação e envolvimento dos empregados na empresa, é que $o$ assunto referente a relações com os sindicatos começou a ser assunto de interesse nas empresas. Segundo Gil (1994, p.141) "o profissional de recursos humanos, seguramente mais do que o de outras áreas, é solicitado a contribuir nesse processo, tanto na negociação direta, quanto no assessoramento à direção geral e de outros escalōes da empresa."

O aspecto referente à atualização do profissional de RH é enfatizado por diversos autores (ver o exemplo, Toledo, 1988; Boog, 1991; Gil, 1994; e Orlickas, 1998). Todos demonstram a necessidade do profissional de RH se autodesenvolver constantemente, a partir de leituras de revistas especializadas, participação em cursos e seminários etc. Além disso, ele precisa ter visão da conjuntura econômica do País, para ter condições de analisar sua influencia na empresa e em sua área de atuação. Necessita ainda ter conhecimento das outras áreas da empresa, para poder medir o impacto de suas ações no negócio.

Outro aspecto que foi apontado como desafio pelos dirigentes foi o relativo à necessidade de RH demonstrar a sua importância às demais áreas como função de apoio às mesmas. Neste sentido, vale destacar, que a 
área de RH precisa apresentar resultados concretos e também desempenhar diversos papéis, como os apresentados por Schuler \& Huber(1993, p.8-14): a) o de estabelecer ligação de RH com as questões e objetivos do negócio; b) o de capacitador, de ser acessível e prestador de serviços para os diversos órgãos da empresa. A tendência deste papel é de partir para a customerization o que significa, ver todos, sejam internos ou externos à organização, como clientes e desta forma colocar o cliente em primeiro lugar. Para os responsáveis por recursos humanos, clientes são os diversos gerentes de linha e de outras áreas. De forma ampliada, clientes compreendem outras organizações e ainda demais empregados; c) o de monitoração, ou seja, verificar se as atividades de RH foram implementadas de forma consistente e justa; d) o de inovador, desenvolver novas abordagens para resolver problemas e fazer benchmarking visando sempre melhoria da produtividade e da qualidade de vida no trabalho levando em consideração a legislação vigente em um ambiente de incerteza e com intensa competição internacional; e) o de adaptador, necessidade de ser mais orientado para o futuro e agir como facilitador das mudanças organizacionais. Por exemplo, com as mudanças no ambiente externo e nas estratégias organizacionais, novas habilidades e competências são necessárias. Para assegurar que tais habilidades e competências estarão disponíveis no tempo certo, o órgão de $\mathrm{RH}$ necessita antecipar tais mudanças e treinar empregados.

Recursos Humanos precisa estar no local da ação e identificado com a organização. Ser consistente na aplicação de suas políticas e ter pró-atividade. Pode assim, mostrar a sua importância às demais áreas, devido ao atendimento com presteza das solicitações recebidas e resolução dos problemas dos diversos clientes.

Os dirigentes das empresas enfatizaram como desafio a utilização da informática como ferramenta facilitadora/agilizadora dos trabalhos de RH. Segundo Schuler (1988, p.23-24), entre as vantagens de utilização da informática para constituição de um bom sistema de informações em RH tem-se: a) o computador conduz o departamento de RH a ter um papel mais ativo no planejamento organizacional; b) o computador integra e armazena num simples banco de dados todas as informaçōes que anteriormente estavam arquivadas em locais separados; desta forma o órgão de RH pode ter uma visão global de seu estoque de pessoal e interpretá-lo de forma mais significativa; c) o computador acelera o processo de compara- 
ção de custos e benefícios na avaliação da ARH; e d) o sistema de informação em RH e a tecnologia da informática facilitam a estocagem fácil e o acesso aos registros de pessoal que são vitais para as organizações.

De acordo com Richards-Carpenter (1996, p.39): "os profissionais de recursos humanos ainda têm um longo caminho a percorrer para conseguir um ótimo desempenho dos seus sistemas informatizados". O expert em sistema de informação em RH acrescenta (ibid, p.39): "melhoria em produtividade, através de diminuição de níveis hierárquicos, transferências do processo decisório e o RH alinhado bem próximo aos objetivos do negócio têm demandado o uso da tecnologia da informação. Se mais melhorias estão para serem atingidas, o uso criativo do computador de forma a administrar pessoas será ainda mais importante." Ainda mais, ele (ibid. p.40) destaca, de acordo com pesquisa desenvolvida pelo IPD - Institute of Personnel and Development e Institute for Employment Studies na Inglaterra, que os sistemas que estavam operando nas empresas com mais freqüência eram os referentes a registros de empregados; folha de pagamento; absenteísmo e férias; administração de recrutamento e seleção e administração de treinamento, estes dois em bem menor escala. O potencial para a automatização dos diversos processos de $\mathrm{RH}$ é imenso. E se a organização está preocupada em reduzir custos, ela precisa procurar saber como utilizar o sistema de informação em recursos humanos computadorizado (SIRHC) de forma mais intensa.

Segundo John (1998, p.38) "hoje, a nova onda de tecnologia está dando ao pessoal de RH a chance de contribuir diretamente para o sucesso do negócio. Embora poucos parecem ainda tê-la utilizado". Ele ainda destaca (1998, p.41) que com a utilização de sistemas de informações computadorizados e integrando às diversas funções de $\mathrm{RH}$ "oferecerá aos profissionais de RH uma fotografia mais acurada da sua força de trabalho e informações objetivas para melhores tomadas de decisão".

Os executivos de RH necessitam dar mais atenção à aplicação da informática aos seus processos, de forma a tornar mais rápido e de fácil acesso a análise dos seus bancos de dados. Assim fazendo, estão indo ao encontro do que os dirigentes esperam que eles desenvolvam nas empresas para que atinjam os seus objetivos de forma mais eficaz. Em países desenvolvidos como a Inglaterra, segundo Arkin (1997, p.43), existem sistemas de informação computadorizados para realização de tarefas como recrutamento interno e planejamento de sucessão que fazem utilização da intranet 
- que são redes privadas cujos web sites podem ser acessados somente por pessoas de dentro daquela organização. Apesar desta ferramenta estar sendo discutida no Brasil (ver Martins, 1996), os conhecimentos são parcos em relação à sua aplicação na área de $\mathrm{RH}$. Existem algumas empresas de consultoria trabalhando na internet para recrutamento e seleção de pessoal (ver Ser Humano, fev. 1998).

Torna-se interessante saber a visão dos executivos de $\mathrm{RH}$ a respeito dos desafios que enfrentam. Tais dados são encontrados na Tabela 2. São os resultados de uma pesquisa, já citada anteriormente, desenvolvida por Oliveira \& Costa (1995).

$\mathrm{Na}$ Tabela 2, pode ser verificado que os executivos de RH priorizaram os seguintes desafios:

- atuar como agente de mudança;

- manter-se tecnicamente atualizado com assuntos ligados à RH;

- criar meios que demonstrem a eficácia de RH;

- obter apoio da direção para planos, programas e ações;

- demonstrar às demais áreas a importância de RH como função de apoio às mesmas.

\section{Tabela 2 - Desafios enfrentados pelos profissionais de $\mathrm{RH}$ Visão dos prórpios executivos da área.}

\begin{tabular}{|c|c|c|c|c|c|c|c|}
\hline \multirow[t]{2}{*}{ Desafios } & \multirow{2}{*}{$\begin{array}{l}N^{\circ} \text { de } \\
\text { casos }\end{array}$} & \multirow{2}{*}{$\begin{array}{l}\text { média } \\
\text { geral }\end{array}$} & \multirow{2}{*}{$\begin{array}{l}\text { desvio } \\
\text { padráo }\end{array}$} & \multicolumn{4}{|c|}{ Grau de concordância (\%) } \\
\hline & & & & CT (1) & $\mathrm{C}(2)$ & $\mathrm{D}(3)$ & DT (4) \\
\hline D6 & 296 & 1,49 & 0,70 & 60,5 & 31,4 & 6,1 & 2,0 \\
\hline D10 & 298 & 1,68 & 0,76 & 46,6 & 41,3 & 9,1 & 3,0 \\
\hline D9 & 297 & 1,78 & 0,80 & 42,1 & 40,7 & 13,8 & 3,4 \\
\hline D4 & 298 & 1,80 & 0,71 & 35,6 & 50,3 & 12,4 & 1,7 \\
\hline $\mathrm{D} 2$ & 298 & 1,82 & 0,82 & 40,3 & 40,9 & 15,1 & 3,7 \\
\hline D5 & 297 & 1,86 & 0,73 & 32,0 & 51,5 & 14,5 & 2,0 \\
\hline $\mathrm{D} 8$ & 298 & 1,88 & 0,74 & 32,6 & 48,0 & 18,1 & 1,3 \\
\hline D3 & 297 & 1,89 & 0,74 & 31,0 & 51,8 & 14,5 & 2,7 \\
\hline D1 & 297 & 1,96 & 0,79 & 29,3 & 50,5 & 15,5 & 4,7 \\
\hline D7 & 297 & 2,06 & 0,89 & 29,6 & 41,4 & 21,9 & 7,1 \\
\hline
\end{tabular}




\section{Lúcia Maria Barbosa de Oliveira}

D1 = manter com o sindicato laboral uma relação madura capaz de gerar satisfação mútua.

D2 = demonstrar à direção a importância da função de RH para atingimento dos objetivos da Empresa.

D3 = demonstrar às demais áreas a importância de $\mathrm{RH}$ como função de apoio às mesmas.

D4 = criar meios que demonstrem a eficácia da área de RH.

D5 = obter apoio da direção para planos, programas e açōes.

D6 = atuar como agente de mudança. balhos.

D7 = utilizar a informática como ferramenta facilitadora/agilizadora dos tra-

D8 = conseguir poder, credibilidade e autonomia para a área de $\mathrm{RH}$.

D9 = planejar as atividades de RH.

$\mathrm{D} 10=$ manter-se tecnicamente atualizado com assuntos ligados a $\mathrm{RH}$.

$\mathrm{CT}=$ concordo totalmente $\mathrm{C}=$ concordo $\mathrm{D}=$ discordo $\mathrm{DT}=$ discordo totalmente

Como pode ser visto, existem algumas concordâncias em relação à visão dos dirigentes e dos executivos de $\mathrm{RH}$, ou seja, ambos acham que o profissional de RH tem como principal desafio atuar como agente de mudança. É realmente de se esperar mudanças radicais de paradigmas. Vale ressaltar, nesse sentido, os resultados de uma pesquisa realizada em 1995 pelo IPD - Institute of Personnel and Development - Instituto de desenvolvimento e Pessoal da Inglaterra a respeito de mudanças para o próximo milênio na administração das pessoas. Conclui que o sucesso nessa administração depende da habilidade de estimular e focar: criatividade, motivação, julgamento, vontade de contribuir, capacidade, adaptabilidade, orientação para o negócio e responsabilidade. Destaca ainda, que o sucesso da administração de recursos humanos não depende só da simples aplicação de técnicas, mas torna-se cada vez mais necessária à mudança de abordagem nos seguintes aspectos:

- necessidade de interdependência entre as diversas área do negócio, equipes de trabalho e forte contribuição individual;

- administração de desempenho para identificar resultados, medir atingimentos e melhoria contínua;

- sistema motivacional para apoiar alcance de resultados, comportamento e desenvolvimento de competência;

- treinamento e desenvolvimento direcionado para as necessidades operacionais, adaptação e crescimento pessoal a longo prazo; 
- esforço consciente para assegurar que tais mudanças são apoiadas e entendidas pela cultura organizacional.

Os dirigentes das empresas estão mais preocupados do que os próprios executivos de $\mathrm{RH}$ no aspecto que se refere a tais profissionais terem boas relaçóes com os sindicatos. Eles necessitam se preparar melhor para enfrentar este desafio indicado pela alta direção das organizaçōes. Sobre este assunto, Toledo (1988, p.88-91) indica contribuiçōes do profissional de $\mathrm{RH}$, de caráter básico universal, que podem ajudar para uma relação madura entre a organização e o movimento sindical: a) desenvolver um trabalho educativo quanto às características do movimento sindical; b) desenvolver políticas uniformes de tratamento de relações sindicais em corporações com várias empresas; c) não confundir relações humanas com relaçōes sindicais; d) manter contato sério e de respeito com os sindicatos; e) procurar negociar dentro de um contexto de diálogo e práticas democráticas; f) possuir sempre um conjunto de informações econômicas que permita uma orientação dos negociadores quanto às verdadeiras conseqüências das reivindicaçôes concretas; e g) revisar a área de salários e benefícios através de um processo de democratização com a participação e envolvimento dos empregados. Schuler \& Huber (1993, p.722-724) também indicam questões básicas para melhoria do processo de negociação entre os sindicatos e a administração das organizaçôes.

Assim, os executivos de RH precisam estar atentos a respeito do que podem fazer e serem pró-ativos no aspecto relativo a sua participação no processo de relacionamento entre os sindicatos e as organizações das quais são parte integrante podendo, portanto, desempenhar um papel-chave.

$O$ desafio que foi considerado importante tanto pelos dirigentes como pelos profissionais de $\mathrm{RH}$ é o referente a que tais profissionais devem manter-se tecnicamente atualizados com assuntos ligados a RH.

Criar meios que demonstrem a eficácia de $\mathrm{RH}$, foi outro desafio apontado por ambos, dirigentes e executivos da área, das empresas pesquisadas. Existem diversas formas de se avaliar a eficácia de $\mathrm{RH}$, por exemplo, as indicadas por Jack Philips e Anson Seers, apud, Connock (1992, p,27) mostradas anteriormente. Ulrich (1998) indica como RH pode se tornar parceiro no negócio e a maneira de atuar de forma a concretizar suas açóes obtendo sucesso. Em síntese (Ulrich p.108) enfatiza que como parceiros 
estratégicos os profissionais de RH precisam: " a) definir uma arquitetura organizacional sendo capazes de utilizá-la para traduzir a estratégia em ação; b) aprender a realizar um diagnóstico organizacional eficaz fazendo boas perguntas e gerando práticas alternativas criativas e oportunas e c) ser capazes de fixar prioridades para as iniciativas e, em seguida, cumprí-las até o fim".

Segundo Schuler \& Huber (1993, p.13) a avaliação da atuação de RH pode ser feita através de uma abordagem quantitativa, por exemplo, na área de seleção pelo número de entrevistas realizadas por cargo e uma abordagem qualitativa, como a opinião da gerência sobre a qualidade do serviço do órgão de RH. Entretanto, eles destacam que a avaliação da contribuição de RH pode ser agrupada em duas categorias: fazer as coisas certas e fazer certo as coisas. A primeira diz respeito a eficácia de $\mathbf{R H}$ em ajudar a empresa a atingir com sucesso os seus objetivos de competitividade, lucratividade, adaptabilidade e implementação de estratégias. Assim as medidas para isso podem incluir, por exemplo: conhecimento das estratégias da empresa e desenvolvimento de programas que estejam alinhados à tais estratégias. A segunda diz respeito eficiência de $\mathbf{R H}$, por exemplo, contratar um profissional bem qualificado para uma área específica.

Desta forma, estão à disposição dos profissionais de RH diversos mecanismos que podem utilizar para demonstrarem resultados da sua atuação. É só agir com pró-atividade e saber adaptar novas técnicas e conceitos à realidade dos contextos interno e externo das empresas onde trabalham.

Os dirigentes priorizaram mais do que os executivos de $\mathrm{RH}$ a aplicação da informática nos trabalhos da área em estudo. Como foi discutido, anteriormente, a informática, sem dúvida, funciona como facilitadora e ferramenta decisiva para agilizar a ação do órgão de RH e sua participação na definição das estratégias do negócio.

Os executivos de RH ainda enfatizaram como um grande desafio para a sua atuação eficaz o seguinte: obter apoio da direção para planos, programas e açōes. Realmente, isto precisa ser realizado. Porém, mais importante do que isto, é a necessidade da liderança de RH estar alocada na alta direção da empresa para que possa participar diretamente das decisões estratégicas da empresa. Mas como foi demonstrado anteriormente, em 34,8\% das empresas pesquisadas no Brasil o órgão de RH está neste nível. Assim, mister se faz, a valorização das atividades de $\mathrm{RH}$, de forma mais objetiva e clara, para que as empresas possam atingir de maneira mais 
rápida e eficaz os seus objetivos. Segundo Tyson (1995, p.45) embora haja incerteza em relação a como $\mathrm{RH}$ estará estruturado nas organizações, o futuro vê o mundo do trabalho mais baseado nas habilidades do que nas organizações. Assim, os profissionais de RH serão demandados, e eles precisarão alargar as suas experiências em aspectos, por exemplo, como administrar e analisar um sistema de informações.

Prahalad (1997, p.7) enfatiza que: "não se deve olhar para uma empresa como uma carteira de produtos, e sim como um conjunto de forças, capacidades e habilidades. Tais forças podem ser reutilizadas para criar novos negócios". Ele ainda adianta que hoje as empresas precisam se preocupar com os ativos invisíveis. Segundo ele a competência essencial é um ativo invisível. E se a empresa quer ter competência essencial ela necessita: a) treinar continuamente as pessoas; b) realocar constantemente as pessoas para aumentar o seu nível de conhecimento; e c) desenvolver os trabalhos em grupo de pessoas até mesmo de níveis organizacionais diferentes para que as competências possam ser desenvolvidas. Assim os profissionais de $\mathrm{RH}$ tem todo um campo fértil para atuarem, mas para isto precisam compreender este novo contexto organizacional e traçarem mecanismos que estejam em concordância com o alcance dos objetivos organizacionais.

Os desafios da área de $\mathrm{RH}$, indicados pelos dirigentes das empresas pesquisadas foram mostrados e discutidos. A área está em transição nos anos recentes no Brasil. Está a exigir do profissional de RH cada vez mais conhecimentos, atualização e meios de conduzir e motivar pessoas para que mesmo com a velocidade das mudanças, as pessoas tenham contínuo crescimento para que possam contribuir na competitividade, na melhoria da qualidade e produtividade na empresa.

\section{Considerações Finais}

O objetivo deste trabalho foi mostrar os principais desafios enfrentados pelos executivos de RH no desempenho de seus papéis sob a ótica dos mesmos e na visão dos dirigentes das empresas. Ficou evidenciado que a manutenção de uma relação madura entre os profissionais de $\mathrm{RH}$ e os sindicatos e a utilização da informática para agilizar e facilitar os trabalhos de tais executivos, constituíram pontos de alguma divergência entre os aspectos salientados pelos grupos estudados. Assim, a alta direção almeja 
profissionais de recursos humanos mais conhecedores de como lidar com os sindicatos, como também, com conhecimentos de informática capazes de tornar a área mais rápida no atendimento aos clientes.

Os executivos de RH também clamaram mais que os dirigentes, o desafio relativo à obtenção de apoio da alta administração para planos, programas e ações.

Já, relativo aos demais desafios, houve uma maior concordância, em relação: à atuação de $\mathrm{RH}$ como agente de mudança; à necessidade de RH mostrar a sua importância como ferramenta de apoio às demais áreas; à necessidade do profissional de RH manter-se atualizado; e à criação de mecanismos que demonstrem a eficácia da área.

Fica claro que os profissionais de recursos humanos têm grandes desafios que são reconhecidos pela alta direção. Evidencia-se também, a necessidade de mudança de paradigmas da área.

Segundo Prahalad (1995,p. 36), nos dias de hoje a competição ocorre nas empresas em três níveis: no produto final, na batalha de preços, e no core de competências visando liderar a evolução de novas indústrias e novos produtos. Ele afirma que nos trabalhos que ele vem desenvolvendo na área de estratégia, a habilidade menos apoiada é a de RH. E para que seus profissionais tornem suas atividades mais valorizadas, devem proceder da seguinte forma: "não começar somente com uma abordagem humanística, mas desenvolver as habilidades das pessoas para que se sintam orgulhosas da empresa onde trabalham" (ibid. p.36). Ele mostra que a competência essencial está na cabeça das pessoas e nas equipes de trabalho. Embora o componente técnico tenha importância, o ponto crucial é a organização social, a capacidade das pessoas compartilharem informaçōes e continuamente tranferirem conhecimentos.

De acordo com Tyson \& Fell $(1995$, p.277-278) seis fatores irão transformar as organizações: a) a maioria das empresas se tornará menor empregando poucas pessoas; b) a hierarquia tradicional cederá lugar a uma variedade de formas de organização, como, por exemplo, rede de trabalho de especialistas; c)os técnicos substituirão os operacionais de fábrica, como trabalhadores de elite, haverá a valorização do trabalho técnico, o conhecimento acumulado está na cabeça das pessoas; d) a divisão do trabalho horizontal substituirá a vertical, as organizações se tornarão mais achatadas; e) os negócios mudarão de fabricação de produtos para a prestação de 
Desafios da Área de Recursos Humanos - Visão dos Dirigentes das Empresas e dos Profissionais da Área de RH

serviços. Em conseqüência haverá uma redifinição do trabalho, o qual se tornará assunto de aprendizagem constante, exigindo grande dosagem do intelecto - o paradigma da aprendizagem organizacional.

Urlich (1998, p.36) diz que: "as organizações bem sucedidas serão aquelas capazes de transformar rapidamente estratégias em ação; gerenciar inteligente e eficientemente os processos; maximizar a contribuição e comprometimento dos empregados; e criar as condições para efetuar mudanças sem deixar marcas". Ele ainda enfatiza que os profissionais de $\mathrm{RH}$ precisam direcionar suas ações para resultados e desenvolverem atitudes para atingí-los.

Tais executivos, necessitam atuar como agente de mudança não só dos processos que irão conduzir como também de si próprios. Mister se faz, a criação de outros paradigmas baseados nos novos contextos que as empresas apresentam, na necessidade de aprendizagem constante e até de certa dosagem de desaprendizagem nas organizações. Eles precisam ser próativos e ágeis suficientes para, por exemplo, traçar programas de treinamento e retreinamento constantes, que ajudem na criação e manutenção da competência essencial das empresas para que estas possam enfrentar de forma mais efetiva a competitividade acirrada.

Os desafios são grandes. Os profissionais de RH precisam estar conscientes do que foi discutido no texto, para ocuparem o seu espaço, hoje, de grande significância nas empresas. Eles podem dar uma efetiva contribuição para o alcance dos objetivos organizacionais, tais como: aumento de produtividade, melhoria de qualidade e ganho de vantagem competitiva.

\section{Referências Bibliográficas}

ARKIN, A. Network solutions. People Management. London: IPD, v.3, n.2, p.43-44, 23 Jan. 1997.

ARMSTRONG, $M$. Human resouces management: a case of the emperor's new clothes? Personnel Management. London: IPM, v.19, n.8, p.3035, Aug. 1987.

. Blue-chip firms with a vision. Personnel Management. London: IPD, v.26, n.10, p.48-53, Oct. 1994.

BOOG, G. G. O desafio da competência - como enfrentar as dificuldades do presente e preparar sua empresa para o futuro. São Paulo: Best-Seller, 1991. 
BOXALL, P. Placing HR strategies at the heart of business sucess. Personnel Management. London: IPD, v.26, n.7, p.32-35, July 1994.

CONNOCK, S. The importance of 'big ideas' to HR managers. Personnel Management. London: IPM, v.24, n.6, p24-27, June 1992.

COOK, R., ARMSTRONG, M. The search for strategy HRM. Personnel Management. London: IPM, v.22, n.12, p.30-33, Dec. 1990.

CURADO, I. B. et alii. Mitos e realidades da gestão de recursos humanos. RAE Light. São Paulo: EAESP/FGV, v.2, n.6,p.6-8, 1995.

EXAME. São Paulo, Editora Abril, ano 30, no.17, edição 616, p.104-110, 14 ago. 1996.

GEORGIADES, N. A strategic future for personnel. Personnel Management. London: IPM, v.22, no.2, p.43-45, Feb. 1990.

GIL, A. C. Administração de recursos humanos: um enfoque profissional. São Paulo: Atlas, 1994.

GONÇALVES, J. E. L. Os novos desafios da empresa do futuro. RAE Revista de Administração de Empresas. São Paulo: FGV, v.37, n.3, p.10-19, jul./set.1997.

GUEST, D., HOQUE, K. Yes, personnel does make a difference. Personnel

Management. London: IPD, v.26, n.11, p.40-44, Nov. 1994.

INSTITUTE OF PERSONNEL AND DEVELOPMENT. Managing people

- the changing frontier: people make the difference - an IPD position paper. London: 12 Jan. 1995.

JOHN, G. A slow application. People Management. London: IPD, v.4, n.13, p.38-44, 25 jun. 1998.

LIVY, B. Corporate personnel management. London, Pitman Publishing, 1988. MÜLLER, R. Contratações pel@ rede. Ser Humano. São Paulo: Segmento, ano XXXII, n.129, p.24-26, fev.1998.

OLIVEIRA, L.M. BARBOSA de., MORAES, W. F. A. de. Coleta de dados realizada por questionário pelo correio: método eficaz? Revista de administração de Empresas. Rio de Janeiro: FGV, v.34, n.4, p.8592, jul./ago.1994.

OLIVEIRA, L. M. Barbosa de., COSTA, S. P. A. da. Conhecimentos, habilidades e atitudes necessários ao profissional de recursos humanos do Brasil. CNPq/FACEPE, jul. 1995. (Relatório de Pesquisa). ORLICKAS, E. Consultoria interna de recursos humanos: conceitos, cases e estratégias. São Paulo: Makron Books, 1998. 
PRAHALAD, C. K. How HR can help to win the future. People Management. London: IPD, v.1, n.1, p.34-35, 12 Jan. 1995.

. A competência essencial. HSM Management. São Paulo: Savana, ano1, n.1, p.6-11, mar./abr. 1997.

RESENDE, E. J. A gestão de pessoal nas empresas brasileiras: o curto e o longo prazo. Tendências do Trabalho. Rio de Janeiro: Tama, n.238, p.7-12, maio, 1994.

RICHARDS-CARPENTER, C. Make a difference by doing IT better.

People Management. London: IPD, v. 2, n.12, p.40-41, 13 June 1996. SCHULER, R. S. Personnel and human resources management. USA: West Publishing Company, 1987.

SCHULER, R. S., HUBER, V. L. Personnel and human resource management. USA: West Publishing Company, fifth edition, 1993 SER HUMANO. São Paulo: AMG \& Editores Associados, ano XXX, n.109, p.17-19, jun. 1996.

TOLEDO, F. de. Recursos humanos crise e mudança. São Paulo: Atlas, 1988.

TOWER PERRIN CONSULTORES. Priorities for Competitive Advantage. A 21st Century Vision: a Worldwide Human Resource Study. USA: IBM, 1991. (Relatório de pesquisa). TRUSS, K. CEOs want a more strategic function. People Management. London: IPD, v.2 n.16, p.36-37, 8 Aug. 1996. TYSON, S., FELL, A. A focus on skill not organization. People Management. London: IPD, v.1, n.21, p.42-45, 19 de Oct. 1995. TYSON, S. Strategic prospects for HRM. London: IPD, 1995. TYSON, S., WITCHER, M. Getting in gear: post-recession hr management. Personnel Management. London: IPD, v.26, n.8, p.20-23, Aug. 1994. ULRICH, D. Os campeões de recursos humanos: inovando para obter os melhores resultados, tradução Cid Knipel. São Paulo: Futura, 1998. . HR with attitude. People Management. London: IPD, v.4, n.16, p. 36-39, 13 Aug. 1998. 